\title{
ARTIGO
}

DOI: $10.22481 /$ praxis.v14i28.3475

\section{CONTROVÉRSIAS JURÍDICAS E A PERSISTENTE DIVISÃO DO TRABALHO EM CRECHES PÚBLICAS: O CASO DE MAUÁ/SP}

\author{
LEGAL DISPUTES AND THE PERSISTENT LABOR DIVISION IN PUBLIC CRÈCHES: \\ THE CASE OF MAUÁ / SP
}

\author{
CONTROVERSIAS JURÍDICAS Y LA PERSISTENTE DIVISIÓN DEL TRABAJO EN \\ GUARDERÍA PÚBLICAS: EL CASO DE MAUÁ/SP
}

\author{
Sanny Silva da Rosa \\ Universidade Municipal de São Caetano do Sul - Brasil
}

Fernanda Feliciano de Andrade

Universidade Municipal de São Caetano do Sul - Brasil

\section{Resumo}

Este artigo discute a divisão do trabalho entre professoras e auxiliares de desenvolvimento infantil em creches públicas, a partir de reflexões sobre a indissociabilidade do binômio cuidar-educar colocado em relevo nos documentos oficiais desde a promulgação da Lei de Diretrizes e Bases de 1996. O texto problematiza os conflitos existentes entre os objetivos declarados na legislação brasileira e as práticas de atendimento em creches, onde persiste a divisão hierárquica das atribuições dos profissionais que trabalham com crianças de 0 a 3 anos. Com base em dados documentais e de campo, coletados em estudo realizado em creches do município de Mauá, região do Grande ABC Paulista, coloca-se em evidência os obstáculos jurídicos e políticos que se interpõem entre os discursos das orientações curriculares e pedagógicas oficiais e as condições necessárias para a sua concretização. Argumenta-se que a definição de regras claras que de fato eliminem as ambiguidades e controvérsias jurídicas que permitem a divisão de papéis no âmbito das instituições de educação infantil é a pedra-de-toque do propósito das políticas públicas de educação infantil de superar a dicotomia cuidar-educar e a herança assistencialista das creches brasileiras.

Palavras-chave: Controvérsias jurídicas. Creche. Divisão do trabalho.

\begin{abstract}
This article discusses the labor division between teachers and nursery assistants in public day care centers, out of the inseparability of the care-educating binomial that has been highlighted in official documents since 1996, when the Brazilian Law of Guidelines and Bases of National Education (LDB) was enacted. The text challenges the existing conflicts between the stated goals of Brazilian legislation and the actual institutional practices, where the hierarchical division between these two professional categories persists. Drawing on documental and field data, collected in a study carried out in crèches of Mauá - municipality located in the metropolitan region of São Paulo - this work points to the legal and political obstacles interposed between Brazilian official discourses and the actual conditions for its
\end{abstract}


implementation. It is argued that the definition of clear rules to eliminate the legal disputes and ambiguities that allow the hierarchical division of these professionals' assignments is the cornerstone of the Brazilian educational policies of overcoming the care-educating dichotomy as well as the inheritance of a humanitarian-assistance conception about crèches social role.

Keywords: Crèche. Labor division. Legal disputes.

\section{Resumen}

Este artículo discute la división del trabajo entre profesoras y auxiliares de desarrollo infantil en guarderías públicas a partir de reflexiones sobre la indisociabilidad del binomio cuidar-educar puesto en relieve en los documentos oficiales desde la promulgación de la Ley de Directrices y Bases de 1996. El texto problematiza los conflictos existentes entre los objetivos declarados en la legislación brasileña y las prácticas de atención en guarderías, donde persiste la división jerárquica de las atribuciones de los profesionales que trabajan con niños de 0 a 3 años. Con base en datos documentales y de campo, recogidos en un estudio realizado en guarderías del municipio de Mauá, ubicado en la región del Gran ABC Paulista, se ponen en evidencia los obstáculos jurídicos y políticos que se interponen entre los discursos de las orientaciones curriculares y pedagógicas oficiales y las condiciones necesarias para su implementación. Se argumenta que la definición de reglas claras que de hecho eliminen las ambigüedades y controversias jurídicas que permiten la división de roles en el ámbito de las instituciones de educación infantil es la piedra de toque del propósito de las políticas públicas de educación infantil de superar la dicotomía cuidar-educar y la herencia asistencialista de las guarderías brasileñas.

Palabras clave: Controversias jurídicas. División del trabajo. Guardería.

\section{Introdução}

Afinal, a quem compete cuidar e educar as crianças pequenas em creches públicas? A questão permanece em aberto frente às controvérsias jurídicas e políticas que se interpõem entre os discursos e orientações pedagógicas oficiais e as condições necessárias para a sua concretização nas instituições de educação infantil. A incontestável persistência da divisão do trabalho entre professores e "auxiliares", particularmente no ambiente da creche, reflete e expõe um nó ainda não desatado pelas políticas públicas de educação infantil mais de vinte anos após a promulgação da LDBEN (Lei de Diretrizes e Bases da Educação Nacional). Este é o tema deste artigo que se propõe a problematizar a questão, com base em estudo que vem sendo realizado em creches públicas na região do Grande ABC Paulista.

Como se sabe, é muito recente na história brasileira a preocupação com a qualidade das instituições de educação infantil e com o atendimento oferecido às crianças pequenas. Diversos estudos (CAMPOS; ROSEMBERG; FERREIRA, 1995; KUHLMANN Jr., 1998, 2000, 2003) já apontaram que somente com a Constituição Federal de 1988 e legislação 
decorrente da LDBEN de 1996 é que a educação infantil foi reconhecida como direito da criança e dever do Estado brasileiro, passando a ser considerada como etapa inicial da educação básica.

Essa mudança de status representou um giro importante do conceito de infância e das concepções associadas ao desenvolvimento, aprendizagem e socialização da criança. Além disso, induziu a adoção de novos discursos acerca do papel e do atendimento oferecido nas instituições de educação infantil, especialmente nas creches, marcadas historicamente por uma concepção assistencialista restrita às noções de guarda e cuidados básicos de crianças pobres (KUHLMANN Jr., 1998). Entretanto, foi apenas quando as políticas públicas globais despertaram para o potencial da educação como "capital" necessário e indutor do desenvolvimento econômico que a tarefa educativa das instituições infantis passou a ser considerada, o que acrescentou novos ingredientes à polêmica sobre o seu papel.

É nesse cenário que o binômio cuidar-educar passa a figurar nos documentos oficiais aludindo ao papel ampliado das instituições e às atribuições dos profissionais de educação infantil. Associado a ele, iniciativas foram tomadas para definir parâmetros, critérios e indicadores de qualidade (BRASIL, 2006, 2009; CAMPOS; ROSEMBERG, 2009) do atendimento ofertado às crianças da faixa etária correspondente a essa etapa inicial da educação básica. Mas, os reconhecidos avanços legais e conceituais esbarram e tropeçam em obstáculos, de ordem política e jurídica, ainda não superados. Essa é uma discussão que passa, sem dúvida, pela formação inicial e pelas atribuições dos profissionais no cotidiano das instituições. Mas vai além, pois depende, antes, da vontade política de superar determinadas barreiras que dificultam a sua concretização. Uma das principais reside nas ambiguidades legais subjacentes à persistente divisão e hierarquização do trabalho de cuidar e educar, particularmente nas creches, de grande parte dos municípios brasileiros.

Esse quadro não é diferente do que se passa na região do Grande $\mathrm{ABC}$ Paulista ${ }^{1}$, mais especificamente no município de Mauá, onde um estudo foi desenvolvido com o objetivo de examinar os desafios encontrados pelos profissionais dos sistemas públicos de educação no manejo dessa situação. A temática aqui apresentada é problematizada a partir das tensões verificadas entre os objetivos declarados na lei e as efetivas práticas de atendimento à criança pequena no ambiente da creche.

\footnotetext{
${ }^{1}$ Região que integra os municípios de Santo André, São Bernardo do Campo, São Caetano do Sul, Mauá, Ribeirão Pires e Rio Grande da Serra, pertencentes à região metropolitana da capital do estado de São Paulo.
} 
Para tanto, este texto foi organizado em torno de três eixos complementares de problematização, cotejados com dados obtidos na referida pesquisa. No primeiro, retoma-se o contexto histórico no qual emerge o binômio cuidar-educar, especialmente nos documentos oficiais da esfera federal, com o intuito de explicitar as tensões entre os objetivos neles declarados e as condições efetivamente oferecidas para o trabalho nas creches. No segundo, discute-se a questão da formação dos profissionais de educação infantil e as tarefas postas sob sua responsabilidade, tanto no plano ideal da legislação maior como no dia a dia das escolas. No terceiro e último tópico, apresenta-se e problematiza-se os obstáculos jurídicos e políticos que subsistem ao discurso da indissociabilidade do cuidar e educar.

\section{De volta para o futuro: da assistência à educação?}

Vinculadas durante longo tempo da história brasileira a organizações filantrópicas e assistenciais, as creches consolidaram-se no imaginário social como instituições associadas ao atendimento aos pobres (KUHLMANN Jr., 1998). E não por outra razão se não pelo fato de que essas instituições foram criadas para atender mães trabalhadoras que não tinham onde deixar os filhos durante sua jornada de trabalho fora de casa.

Para oferecer abrigo e cuidados básicos à criança pequena, em geral, as primeiras instituições dispunham de instalações precárias, improvisadas e com parcos recursos materiais (LORDELO; CARVALHO; KOLLER, 2002), situação que pouco se alterou ao longo do tempo, conforme apontam estudos recentes (CAMPOS, et.al, 2011) sobre a qualidade da educação infantil em capitais brasileiras. Além disso, o atendimento invariavelmente ficou a cargo de mulheres voluntárias e sem formação específica, sob "a justificativa - implícita ou explícita - de que ser mulher constitui requisito necessário e suficiente para o exercício da atividade..." (MONTENEGRO, 2005, p.82).

Os estudos de Kuhlmann Jr. (1998, 2000) apontam que as primeiras instituições de abrigo à infância no Brasil, ainda no século XIX, também cumpriam funções de controle social e proteção da sociedade contra potenciais ameaças resultantes de atos de transgressão de crianças abandonadas. De acordo com o autor:

[...] a história da assistência tem sido também a da produção de uma imagem do pobre como ameaça social a ser controlada. As instituições cumpririam uma função apaziguadora. Interpreta-se a pobreza a partir de caracterizações parcializadas. Essa lógica ainda se faz presente quando se reduz a história da infância à da infância abandonada, quando a criança 
pobre é identificada como menino de rua, que, por sua vez, torna-se sinônimo de trombadinha, ou menor infrator, reproduzindo a concepção de pobreza forjada nos moldes das concepções assistenciais do início do século. (KUHLMANN JR., 1998, p. 28, grifos do autor).

Esse imaginário persistiu ao longo do século XX e se expressou na vinculação das creches às secretarias e departamentos de assistência e bem-estar social até que ocorresse sua reestruturação administrativa, técnica e pedagógica por força do reconhecimento dos direitos da criança pela Constituição Federal de 1988 (BRASIL, 1988), pelo Estatuto da Criança e do Adolescente (ECA) de 1990 (BRASIL, 1990) e pela LDBEN de 1996 (BRASIL, 1996). Vale registro que esses avanços legais são tributários, em grande parte, das conquistas dos movimentos sociais e de mulheres de todo o país, com destaque para a luta por creches de mulheres operárias da região do Grande ABC Paulista no final dos anos 1970 e ao longo da década de 1980 (ROSEMBERG, 1984; SCHIFINO, 2016).

A história de uma das creches municipais de Mauá, registrada no Projeto PolíticoPedagógico da instituição (MAUÁ, 2015) confirma esse histórico: inaugurada em 1988, começou a funcionar em apenas 3 salas que acomodavam também as crianças da pré-escola, de 4 a 6 anos. Em 1999, a unidade passou a contar com uma cozinha e uma brinquedoteca. "Nos muros instalaram portões que davam acesso às quatro salas de madeira onde eram atendidos os alunos das [diferentes] fases". Somente em 2009, com recursos do PDDE (Programa Dinheiro Direto na Escola), do governo federal, a creche pôde investir em materiais pedagógicos e de uso permanente, quando passou a funcionar em novas instalações, cujas obras foram concluídas anos mais tarde, em 2014.

Considerando as características da comunidade atendida, o hiato entre passado e presente é pouco significativo: a escolaridade da maioria dos pais não passa do ensino médio e a renda média das famílias varia entre $\mathrm{R} \$ 1.001,00$ a $\mathrm{R} \$ 2.000,00$. Esse perfil explica em grande medida a expectativa dos pais de encontrar na creche "um lugar que cuide de seus filhos", sendo secundária a preocupação com o "desenvolvimento pedagógico" (MAUÁ, 2015).

As mudanças da legislação educacional brasileira, nos anos 1990, intensificaram o debate sobre o que caracteriza as atividades de cuidado (tradicionalmente associadas às necessidades básicas de guarda, alimentação, saúde e higiene) e as atividades entendidas como educativas ou pedagógicas (associadas ao desenvolvimento e à aprendizagem). Assim, o binômio cuidar-educar apareceu, tanto nos documentos curriculares, como nas discussões 
sobre os conteúdos e saberes necessários à formação dos profissionais que atuam em creches e pré-escolas.

Montenegro (2005) recorda que foi no documento Política Nacional de Educação Infantil, elaborado em 1993 pela Coordenação Geral de Educação Infantil (COEDI) do Ministério da Educação (BRASIL, 1994), que se encontram as primeiras referências à indissociabilidade das dimensões do cuidado e educação. Nele, as diretrizes para o atendimento oferecido em creches e pré-escolas foram estabelecidas a partir de uma concepção mais ampla e teoricamente mais consistente sobre a criança.

Nas diretrizes pedagógicas que aqui são explicitadas, a criança é concebida como um ser humano completo que, embora em processo de desenvolvimento e, portanto, dependente do adulto para sua sobrevivência e crescimento, não é apenas um "vir a ser". Ela é um ser ativo e capaz, motivado pela necessidade de ampliar seus conhecimentos e experiências e de alcançar progressivos graus de autonomia frente às condições de seu meio. (BRASIL, 1994, p.16).

Em Mauá, município que se caracteriza ${ }^{2}$ pela atividade industrial da região, esse debate chegou em 1997, logo após a promulgação da LDB, quando a responsabilidade das creches migrou da Secretaria de Assistência Social para a Secretaria da Educação. Um dos primeiros sinais das repercussões da nova lei foi a substituição da nomenclatura das creches, antes designadas em referência a personagens de histórias infantis - como Frajola, Piu-Piu, Sininho e outros - por nomes de figuras eminentes vinculadas à história da cidade.

De acordo com o histórico registrado no RCE (Referencial Curricular de Educação) do município, a mudança dos nomes "realça a importância dada a essas instituições como escolas” e não “apenas de cuidado e recreação das crianças” (MAUÁ, 2012, p.19, grifo nosso). A um leitor atento não passa despercebido que, ao preocupar-se em enfatizar o caráter "educativo" do trabalho da creche, o discurso das novas políticas públicas locais escorrega na semântica das noções de cuidado e recreação deixando entrever, no uso do advérbio "apenas", que ainda são vistas como funções menos importantes.

Assim, se há certo consenso de que educação se refere aos processos cognitivos, afetivos e sociais que antecedem a escolarização, o significado da noção de "cuidado" permanece pouco preciso e bastante polêmico. Maria Malta Campos (1994, p. 35), observou

\footnotetext{
2 A população total de Mauá, em 2017, alcançou 447.911 habitantes, segundo a Fundação Seade <http://www.perfil.seade.gov.br〉. Na composição do PIB do Município de Mauá, o setor de serviços responde por $50,77 \%$, a indústria por $35,72 \%$ e os impostos por $13,50 \%$; embora seja a $11^{\mathrm{a}}$. maior cidade do Estado de São Paulo, é a $10^{\text {a }}$. mais pobre em orçamento per capita, de acordo com informações do site da Prefeitura Municipal de Mauá. 〈http://www.maua.sp.gov.br/PerfilMunicipal>
} 
que o cuidado se associa às atividades de alimentar, lavar, trocar, curar, proteger, consolar, mas que todas fazem parte do que chamamos de educar. A mensagem enfatizada pela autora é que essa indissociabilidade pressupõe compreender que, ao cuidar, educamos, e que o ato de educar expressa e inclui a preocupação (cuidado) com o outro.

Embora aparentemente óbvia, essa articulação não foi suficientemente elaborada do ponto de vista conceitual. As ponderações de Montenegro (2005) nos ajudam a compreender as razões da tendência a se operar uma separação entre esses dois termos. Para ela, isso se deve à frequente polarização entre as funções relacionadas à afetividade e à racionalidade no campo da educação infantil. Vejamos como a autora explica esse fenômeno, que se expressa na divisão de tarefas entre professoras e suas "auxiliares", sobretudo no contexto da creche. Diz ela:

A cisão entre o considerado racional (educar) e irracional ou emocional (cuidar) se reveste de conotação hierárquica, uma vez que, na educação infantil, encontramos atuando, muitas vezes conjuntamente, a auxiliar que "cuida" (limpa, troca, dá comida, acalma, atende às necessidades afetivas, etc.) e a professora que desenvolve atividades pedagógicas (transmite conhecimentos sistematizados, programa atividades, trabalha a cognição). (MONTENEGRO, 2005, p. 84).

Essa cisão foi também discutida, de forma muito pertinente, por Tiriba (2005), no texto "Educar e cuidar ou, simplesmente, educar?" Esta autora chama a atenção para o fato de que, histórica e filosoficamente, a distinção razão/emoção, corpo/mente - típica do pensamento ocidental - encontra-se na origem da divisão hierárquica, mas também de gênero, que entende o cuidado como atividade menos importante, relacionada ao corpo, e a educação, com fins mais elevados, relacionados à razão ou ao espírito.

Desde Platão, a tradição filosófica ocidental assume a emoção como pouco produtiva ou mesmo prejudicial aos processos de construção do conhecimento. Oposta à razão - assumida como faculdade indispensável ao desvelamento e compreensão da realidade - a emoção é associada ao irracional, ao natural, ao particular, ao privado e ao feminino. Em contrapartida, a razão é associada ao mental, ao cultural, ao universal, ao público e ao masculino. Mas é num contexto sócio-histórico, em que o capitalismo emergente se alia à ciência com o propósito de transformar a natureza em matéria morta para a produção de mercadorias, que os valores e as emoções são neutralizados pelo método científico com objetivo de obtenção de conhecimentos fidedignos. (TIRIBA, 2005, p.6).

No contexto escolar, essa cisão se faz perceptível na forma como algumas professoras de educação infantil procuram desvincular suas atribuições (pedagógicas) de atividades consideradas menores. Um exemplo extraído de pesquisa realizada pela autora ilustra bem a 
presença dos resquícios da tradição escravista brasileira, de acordo com a qual determinadas tarefas, consideradas "domésticas" e antes realizadas por mulheres escravizadas, até hoje são destinadas, em ambientes familiares, a mulheres das classes populares. E, nas creches, às "auxiliares". Nas palavras de uma professora:

Eu não faço isso, eu estou aqui para ensinar eu não estou aqui para cuidar"; então a ela [professora]não cabe levar a criança ao banheiro, limpar um bumbum, colocar a criança para escovar os dentes, colocar a criança para repousar, não cabe a ela isso, eu acho que essa é uma questão que pode mudar, tem que mudar não é? (TIRIBA, 2005, p. 3, grifo nosso).

Como se vê, a dicotomia cuidar-educar não se deve apenas a uma dificuldade de compreensão conceitual. Questões históricas e sociais explicam a persistência de equívocos que, em verdade, se fundam em preconceitos, principalmente de classe. Reforçar a indissociabilidade entre esses termos parece, no plano do discurso, não ser não suficiente para romper com a tradição assistencialista das instituições responsáveis pela primeira infância. Ainda assim, é importante reconhecer que as conquistas decorrentes da nova legislação educacional brasileira impulsionaram os poderes públicos municipais a adotarem medidas até recentemente inéditas nas creches brasileiras.

No caso de Mauá, em 1997, as escolas de educação infantil (creches e pré-escolas) passaram a contar com um dirigente próprio e uma equipe gestora; em 1998, foi instituído o HTPC (Horário de Trabalho Pedagógico Coletivo); e, em 2002, com a construção de novas unidades, o número de vagas foi ampliado. Entretanto, o atendimento à demanda permanece deficitário, como informa pesquisa recente sobre o direito à educação e a judicialização das vagas em creches desse município (POLONI, 2017).

Dados da Secretaria Municipal de Educação de Mauá, aferidos pela pesquisadora, dão conta que o número de crianças matriculadas é bem superior à capacidade física da rede, cujo déficit, em 2016, chegou a 426 vagas. Somadas a estas, no mesmo ano, outras 1.599 crianças encontravam-se em "lista de espera”, situação que de acordo com Maria José Poloni (2017, p. 145) "altera o módulo de sala de aula e, em consequência o trabalho realizado pelos docentes, comprometendo o cuidar e o educar na educação infantil. “ Mais do que isso, estimula a contratação de profissionais com formação em nível médio para "auxiliar" as professoras e, em consequência, reforça a divisão hierárquica relacionadas ao educar e cuidar.

Costuma-se apostar que a superação de tais dicotomias depende de investimentos na formação dos profissionais de educação infantil. Contudo, essa tese deixa de algum modo subentendido que a responsabilidade pelas distorções observadas no cotidiano das instituições 
seria, em última instância, dos próprios profissionais da educação. Ora, se a persistência de tal imaginário é fruto de uma longa tradição histórica que dividiu e hierarquizou essas tarefas, parece claro que a reversão de tal estado de coisas depende da adoção de políticas públicas que, efetivamente estanquem as práticas assistencialistas de atendimento à infância e cuidem dessa etapa inicial da educação básica como direito da criança pequena à proteção e à educação.

Nesse sentido, a indissociabilidade desse binômio, proclamada nos documentos oficiais, pressupõe o comprometimento dos formuladores de políticas com um aparato legal, programas e medidas que não apenas incentivem a articulação cuidar-educar no plano do discurso pedagógico, mas como parte da construção de uma nova cultura educacional que extinga a hierarquização do trabalho nas instituições de educação infantil. Essa disposição, porém, parece distante da realidade dos municípios, responsáveis que são pela etapa inicial da educação básica.

A divisão de tarefas entre professores e auxiliares de educação infantil já foi examinada em diferentes estudos (CERISARA, 1999; KISHIMOTO, 2004; BONETTI, 2005; GOMES, 2009; NUNES; CORSINO; KRAMER, 2013), os quais convergem quanto às danosas implicações para a formação, profissionalização e práticas docentes. Esse tema será examinado no próximo tópico, que aborda e contrasta as concepções defendidas por pesquisadores da educação infantil, os objetivos declarados na legislação e as responsabilidades das profissionais de educação no dia a dia das creches.

\section{Cisões persistentes das políticas de formação e trabalho na Educação Infantil}

Com a promulgação da LDB, a formação de professores para a educação infantil foi incluída na pauta geral de discussões sobre a formação dos docentes da educação básica. De acordo com o art. 62 da Lei 9394/96, essa formação passaria a ser realizada em nível superior, em cursos de licenciatura plena. Por essa época, e mesmo antes, alguns pesquisadores e especialistas já vinham defendendo a especificidade epistemológica deste campo, apontada em documento elaborado pela Coordenação Geral de Educação Infantil do Ministério da Educação (BRASIL, 1994).

Maria Lúcia Machado (1999) postulou, com base no referencial teórico de Vygotsky (1988), uma Pedagogia das Interações para fundamentar projetos político-pedagógicos de instituições de educação infantil. De acordo com a autora, essa pedagogia contemplaria o 
cuidar e o educar como condição para a aprendizagem e desenvolvimento próprio da criança. Crítica do modelo escolar adotado em creches e pré-escolas, defendeu uma educação infantil que valorizasse as brincadeiras, o contato da criança com a natureza, com diferentes linguagens artísticas, entre outras experiências que dependem da intermediação dos adultos.

No artigo citado, denunciou os procedimentos "caricatos" das "escolinhas" onde crianças se deslocam "andando em filas" ou permanecem "sentadas em mesas olhando para uma lousa, realizando exercícios repetitivos" (MACHADO, 1999, p.86). Para a autora, uma pedagogia focada na interação social como espaço de desenvolvimento psicológico deveria também pautar a formação dos profissionais que atuam com crianças em idade pré-escolar.

Nessa mesma linha de argumentação, Eloisa Rocha (2001), defendeu uma Pedagogia da Educação Infantil, justamente pela especificidade desse campo que se diferencia das funções escolarizantes das demais etapas da educação básica. Para esta autora, há um marco diferenciador entre as instituições de educação infantil e a escola, pois:

Enquanto a escola se coloca como o espaço privilegiado para o domínio dos conhecimentos básicos, as instituições de educação infantil se põem sobretudo com fins de complementaridade à educação da família. Portanto, enquanto a escola tem como sujeito o aluno, e como o objeto fundamental o ensino nas diferentes áreas, através da aula; a creche e a pré-escola têm como objeto as relações educativas travadas num espaço de convívio coletivo que tem como sujeito a criança de 0 a 6 anos de idade (ou até o momento em que entra na escola). (ROCHA, 2001, p. 31, grifos da autora)

Para demarcar essa posição, a autora denomina as instituições de educação infantil como "espaços não-escolares", uma vez que o trabalho com crianças pequenas diz respeito aos processos mais gerais de sua constituição, como "a expressão, o afeto, a sexualidade, a socialização, o brincar, a linguagem, o movimento, a fantasia, o imaginário" (ROCHA, 2001, p. 31). Por essa razão, o conjunto de relações que a criança estabelece com a natureza, com o meio social, com os adultos e com outras crianças constituem conhecimentos específicos de uma Pedagogia da Educação Infantil.

Assim, segundo Rocha (2001, p. 31), o objeto da Pedagogia da Educação Infantil seria “a própria criança: seus processos de constituição como seres humanos em diferentes contextos sociais, sua cultura, suas capacidades intelectuais, criativas, estéticas, expressivas e emocionais." Sendo assim, outros conhecimentos que não os relativos ao "ensino" e aos processos cognitivos valorizados pelo paradigma escolar deveriam integrar os conteúdos formativos dos profissionais que atuam em creches e pré-escolas. 
Mas, como bem observado por Gatti, Barreto e André (2011), na esfera das ações governamentais, são as políticas de currículo que definem o que deve ser ensinado e aprendido e, nessa medida, são elas que orientam as políticas de formação inicial e continuada de professores. Encontramo-nos, aqui, no campo das políticas públicas - e não no plano ideal - terreno onde os objetivos "reais" se chocam com os objetivos "proclamados", no dizer de Saviani.

Enquanto os objetivos proclamados se situam num plano ideal onde o consenso e a convergência de interesses é sempre possível, os objetivos reais situam-se num plano onde se defrontam interesses divergentes e por vezes antagônicos, determinando o curso da ação as forças que controlam o processo. (SAVIANI, 1997, p. 190)

Pois bem, na contramão dos esforços realizados inicialmente pela equipe da COEDI/MEC (1994) no sentido de enfatizar a especificidade de uma pedagogia da infância, o governo de Fernando Henrique Cardoso lançou o RCNEI (Referencial Curricular Nacional para a Educação Infantil, em 1998. Embora mantendo alguns dos princípios postulados pela equipe anterior, o RCNEI imprimiu um sentido "escolarizante" à proposta, que se evidencia na didatização dos temas e conteúdos nele contemplados (KUHLMANN JR., 1999; CERISARA, 2002).

Para cumprir seus "reais" objetivos, esse material foi amplamente distribuído nos sistemas de ensino de todo o território nacional, passando a orientar a organização e funcionamento de creches e pré-escolas e, como desdobramento, os conteúdos trabalhados na formação inicial e continuada de professores. Alinhavava-se, assim, um projeto mais amplo das políticas de "resultado" em todas as etapas da educação básica, por meio da padronização curricular e avaliações de larga escala.

A consolidação de todo esse processo ganhou corpo nas décadas seguintes e, mais recentemente, com a BNCC (Base Nacional Comum Curricular) para a Educação Infantil, cujos objetivos de "aprendizagem e desenvolvimento", desde o primeiro ano de vida do bebê, são detalhadamente descritos e codificados para facilitar o "monitoramento das práticas pedagógicas" dos educadores. Nessa direção, mais um passo foi dado, com a publicação, em julho de 2017, da Portaria 826 do MEC (BRASIL, 2017b). Essa normativa inclui alunos de pré-escola no PNAIC (Programa Nacional de Alfabetização na Idade Certa), que prevê avaliações periódicas de larga escala nas áreas de alfabetização e matemática. Não passou despercebido que um dos compromissos do atual PME (Plano Municipal de Educação) de 
Mauá, é a implantação da "avaliação da educação infantil, com base nos parâmetros nacionais de qualidade" (MAUÁ, 2015, p.2).

Voltando ao tema da formação, vale lembrar que após idas e vindas da legislação, sabe-se que o lócus formação de professores de educação infantil acabou se concentrando nos cursos de Pedagogia, cujas diretrizes curriculares só foram definidas dez anos após a promulgação da LDB, em $2006^{3}$. Dos embates entre os que se posicionaram por uma formação de professores mais voltada às práticas e o que postulavam a importância de uma sólida formação teórica, resultou um texto híbrido que apenas confirma a falta de foco das diretrizes curriculares desse curso. Nas palavras de Saviani:

O resultado nos coloca diante do seguinte paradoxo: as novas diretrizes curriculares nacionais do Curso de Pedagogia são, ao mesmo tempo, extremamente restritas e demasiadamente extensivas: muito restritas no essencial e assaz excessivas no acessório. São restritas no que se refere ao essencial, isto é, àquilo que configura a pedagogia como um campo teóricoprático dotado de um acúmulo de conhecimentos e experiências resultantes de séculos de história. Mas são extensivas no acessório, isto é, se dilatam em múltiplas e reiterativas referências à linguagem hoje em evidência (...) (SAVIANI, 2007, p. 127).

Em termos práticos, os currículos dos cursos de Pedagogia preveem temas e conteúdos tão abrangentes que é impossível contemplá-los nas exíguas 3.200 horas de sua carga horária total, parte das quais as instituições de ensino superior - em sua maioria privadas - encontram brechas para reduzir o tempo de efetivo trabalho acadêmico em sala de aula e, por consequência, custos. Não surpreende que estudos tenham constatado o caráter fragmentário e disperso dos currículos dos cursos presenciais de Pedagogia (GATTI; NUNES, 2009), sem falar no crescimento exponencial da modalidade a distância, cuja qualidade já foi severamente questionada (BARRETO, 2015).

Estudos de Marin e Giovanni (2007, 2013) sobre formação de professores demonstram que os alunos têm saído do ensino superior na condição de "despossuídos" dos recursos necessários à compreensão de leituras e à elaboração intelectual de conceitos básicos de seu campo de atuação. Em condições similares a estas, e mais intensivamente na segunda metade dos anos 2000, trabalhadores de creches e pré-escolas passaram a buscar a almejada/exigida formação em nível superior, logrando obter certificação em curto espaço de tempo e com

\footnotetext{
${ }^{3}$ Conforme Parecer, CNE/CP 3/2006, aprovado em 21 de fevereiro de 2006, homologado em abril do mesmo ano, subsumido na Resolução n. 2 de $1^{\circ}$ de julho de 2015 , que definiu diretrizes curriculares nacionais para formação inicial, em nível superior, dos cursos de licenciatura e formação continuada de professores da educação básica.
} 
relativa "facilidade". Porém, sem garantia de que os conhecimentos, neles literalmente "adquiridos", resultem em efetiva contribuição à sua formação profissional.

A pesquisa que fundamenta este estudo mapeou, em 2016, o perfil de formação dos profissionais que atuam nas 27 creches de período integral do município de Mauá. Os dados mostram que $100 \%$ das 181 professoras e das 21 professoras-coordenadoras pedagógicas que responderam aos nossos questionários - todas mulheres - possuem formação em nível superior. E, embora não exigido para o cargo, 51\% das 101 Auxiliares de Desenvolvimento Infantil (ADI) têm diploma de Pedagogia, a maioria (81\%) em instituições privadas, o que confirma as estatísticas nacionais ${ }^{4}$ quanto ao predomínio do setor privado na formação inicial de professores.

Embora não tenham sido indagadas a respeito, não seria arriscado afirmar que a motivação que as levou a ir em busca do ensino superior foi a exigência de "cumprir a lei" e a esperança de, com a chancela do diploma, ascender à e na carreira do magistério. Contudo, obstáculos jurídicos insistem em se interpor entre os objetivos proclamados na legislação e as práticas políticas de (des)valorização do magistério.

Sobre isso, vale mencionar o alerta feito recentemente - uma vez mais por Dermeval Saviani (2016) - por ocasião dos 20 anos da promulgação da LDB. Sobre o artigo 62 da LDB, que estabeleceu como regra a obrigatoriedade da formação dos professores em cursos de nível superior, o autor observa a existência de uma "falha" de redação que sustenta, até hoje, a divisão de trabalho problematizada neste texto, particularmente nas creches.

Ao admitir, no corpo do artigo que fixa a regra, a sua exceção - ou seja, a formação em nível médio para professores de educação infantil e anos iniciais do ensino fundamental tal "falha técnica" vem cumprindo a função de favorecer, de forma permanente, tanto as escolas privadas que porventura mantêm cursos de magistério nesse nível de ensino, como os poderes públicos municipais que, desse modo, encontram amparo legal para a contratação de profissionais de educação não incorporados à carreira docente. Vale registro que essa “exceção’ já foi ratificada diversas vezes, sendo a última pela Lei 13.415, de 16 de fevereiro de 2017 (BRASIL, 2017a). Evidencia-se, assim, o interesse dos formuladores de políticas em manter inalterada essa situação.

\footnotetext{
${ }^{4}$ De acordo com dados do Censo da Educação Superior (MEC/INEP), de 2013, o setor privado era responsável por $45,61 \%$ do total de matrículas nos cursos de licenciatura presenciais do País; e, na modalidade a distância, por $78,32 \%$.
} 
No município de Mauá, a dicotomia cuidar-educar evidencia-se na distinção das atribuições dos cargos públicos de Professor e Auxiliar de Desenvolvimento Infantil, conforme quadro a seguir.

Descrição Sumária de Cargos na Educação Infantil - Município de Mauá, SP

\begin{tabular}{|c|c|}
\hline Professor I - Ed. Infantil & Auxiliar de Desenvolvimento Infantil \\
\hline $\begin{array}{l}\text { Organiza e promove as atividades educativas, } \\
\text { levando as crianças a se exprimirem através } \\
\text { de desenhos, pintura, conversação, canto ou } \\
\text { por outros meios e ajudando-as nestas } \\
\text { atividades, para desenvolver física, mental, } \\
\text { emotiva e socialmente os educandos em } \\
\text { idade pré-escolar. }\end{array}$ & $\begin{array}{l}\text { Compreende as tarefas que se destinam a } \\
\text { executar sob supervisão, serviços de } \\
\text { atendimento às crianças em suas } \\
\text { necessidades diárias, cuidando da } \\
\text { alimentação, higiene, recreação e educação. }\end{array}$ \\
\hline
\end{tabular}

Fonte: Anexo VII - Decreto n. 6.433 de 28 de maio de 2003, Município de Mauá (grifos nossos)

Fica nítido na descrição dos cargos que, ao professor compete a responsabilidade pela dimensão intelectual do trabalho, como "organizar e promover" atividades educativas, enquanto ao ADI cabe a "execução" de tarefas e "serviços", "sob supervisão" do professor e de outros profissionais hierarquicamente superiores a ele. Isto porque, como observado por Tiriba (2005), as funções ligadas aos aspectos racionais e cognitivos são social e culturalmente mais valorizadas, enquanto que atender as necessidades associadas ao corpo, como alimentação e higiene, ainda são tarefas consideradas "menores".

Contudo, chama a atenção que, embora tais atribuições sejam funcionalmente hierarquizadas, a descrição dos cargos não logra eliminar a alusão às dimensões "educativa" e de "cuidado" inerentes ao trabalho de um e de outro. E isso porque, no trato direto com as crianças, é impossível dissociar as práticas e os efeitos das ações de cuidar e educar. De fato, não é tarefa simples encontrar meios de justificar, artificialmente, uma separação a rigor impossível, posto que a criança é um ser integrado e indivisível. Mais do que um problema pedagógico, trata-se de uma questão legal, como apontam as pesquisadoras de um estudo realizado recentemente em municípios do Rio de Janeiro:

É importante ressaltar a ilegalidade de contratação de auxiliares com função docente. A Educação Infantil, como primeira etapa da educação básica, exige a presença de professor junto aos grupos de crianças. $\mathrm{O}$ cargo de auxiliar precisa ser discutido e as atribuições desse profissional nas creches e pré-escolas, melhor definidas. (NUNES; CORSINO; KRAMER, 2013, p.176). 
Enquanto isso, persistem as barreiras jurídicas e políticas que dificultam a sutura de tais cisões, algumas das quais são tratadas no próximo tópico.

\section{Controvérsias jurídicas e a persistente divisão do trabalho na educação infantil}

Em grande parte dos municípios brasileiros, essa divisão do trabalho na educação infantil, particularmente nas creches, permanece como realidade aparentemente insolúvel. Como já antecipamos, a grande brecha reside na ambígua redação do artigo 62 da LDB, mas não só. No emaranhado dos textos legais, encontram-se outras argumentações jurídicas que dão sustentação à "legalidade" de tal situação.

Respondendo a uma consulta do município de Jaú, São Paulo, sobre a possibilidade de inclusão na carreira do magistério das "recreadoras de creches" que possuem habilitação exigida e, por extensão, sobre o direito dessa categoria à remuneração condizente, com recursos do FUNDEB (Fundo de Desenvolvimento da Educação Básica e Valorização dos Profissionais da Educação), o Conselho Nacional de Educação (CNE) emitiu o Parecer CNE/CEB n. 7/2011. Fazendo referência aos princípios da igualdade, da finalidade e motivação, o parecer reiterou posição favorável, anteriormente emitida no Parecer CNE/CEB no 21/2008, à regularização da situação dos “auxiliares”, com o seguinte argumento:

[...] a existência de profissionais que atuam na Educação Infantil com a formação pedagógica adequada, mas que não integram regularmente a carreira de magistério, acarreta seu enfraquecimento e sua desvalorização, além de desatender à Constituição e aos preceitos legais. Sua integração na carreira deve, portanto, vir a ser regularmente possibilitada. (BRASIL, 2011, p. 10)

Entretanto - e sempre há um "porém" - o voto do relator definiu as condições mediante as quais seria possível tal "enquadramento":

O enquadramento do servidor em cargo diverso do original é possível e é legal quando se tratar de servidor efetivado no órgão em que se dará a recolocação e quando tenha se submetido a concurso público similar em dificuldade e exigências ao realizado para o cargo em que se dará o novo provimento, e quando houver similaridade nas atribuições do cargo. (BRASIL, 2011, p. 10, grifos nossos).

Bem se vê que embora a primeira linha de raciocínio sugira posição favorável à integração desses profissionais na carreira do magistério, o voto do relator apresenta a "condição" jurídica para que seja possível tal "enquadramento". Começam aqui as 
dificuldades impostas por outros dispositivos legais, que abrem brechas para a manutenção da divisão de cargos e funções na educação infantil. Isto porque basta que os municípios se valham, por exemplo, do expediente de abertura de editais de concursos públicos para "auxiliares" (ou outras denominações equivalentes), cujas atribuições não se equiparem às dos professores, por meio de processos seletivos com diferentes graus de "exigência" e "dificuldade", para que consigam escapar de possíveis questionamentos e ações judiciais.

Mas a polêmica se estende e se desdobra em questões de ordem conceitual. Pois diferentes nomenclaturas são utilizadas para designar os "profissionais do magistério". Assim, quem, para efeito de carreira e benefícios do FUNDEB, poderia receber essa designação profissional para o magistério na educação básica? A resposta do CNE questionamento da APEOSP (Sindicato dos Professores do Ensino Oficial do Estado de São Paulo) foi emitida no Parecer CNE/CEB n. 24/2007, homologado em 2008, no qual, após incursão em artigos de diversas Leis, Pareceres e Resoluções, concluiu que: "são equivalentes, em termos conceituais, as denominações trabalhadores da educação, profissionais da educação, profissionais da educação escolar e profissionais do magistério". Portanto,

[...] o conceito de "magistério da Educação Básica" (...) deve ser entendido como trabalho/função de ensino a cargo e desenvolvido/exercida por professores, na qualidade de profissionais da educação escolar/ensino, em todos os níveis e modalidades de ensino da Educação Básica presencial. (CNE/CEB 24/2007, p.6, grifos nossos).

A definição parece não resolver a questão de fundo quanto ao lugar dos "auxiliares", pois embora as Diretrizes Curriculares Nacionais da Educação Infantil (BRASIL, 1999) orientem que as instituições devem promover em suas propostas pedagógicas "práticas de educação e cuidados, que possibilitem a integração entre os aspectos físicos, emocionais, afetivos, cognitivo/linguísticos e sociais da criança, entendendo que ela é um ser completo e indivisível" (grifos nossos); e mesmo sendo reconhecida, pelo Parecer CNE/CEB 24/2007, como de "absoluta necessidade" a existência de profissionais que desempenham funções na Educação Infantil para dar conta dessas exigências, a formação adequada não é suficiente para que sejam considerados "profissionais do magistério". Isto porque outras condições são necessárias - esclarece o Parecer - dentre as quais, o ingresso por meio de concurso público de provas e títulos, em conformidade a Emenda Constitucional n. 53/2006 que alterou o inciso V do art. 206 da Constituição Federal (BRASIL, 2007).

Com tal argumento, a questão retorna à disposição política dos municípios, tendo em vista a garantia constitucional de autonomia de que dispõem para driblar possíveis 
questionamentos, via dispositivo de concursos públicos diferenciados para professores e auxiliares. Como a evidenciar as dificuldades políticas envolvidas na questão, o Parecer CNE/CEB 21/2008 ainda "aguarda homologação" do Ministro, enquanto o Parecer CNE/CEB 7/2011 foi arquivado por despacho de 25/02/2013.

Em meio a tais controvérsias, Mauá havia aprovado, pela Lei 4.135, de 2 de fevereiro de 2007 (MAUÁ, 2007), o Estatuto do Magistério Público do Município. Nele constavam, nos artigos 14, 15 e 16 das Disposições Transitórias, regras para o enquadramento dos Auxiliares de Desenvolvimento Infantil (ADI) no Quadro do Magistério da Secretaria Municipal de Educação, desde que tivessem a formação exigida para o exercício do cargo de Professor na faixa etária de 0 a 3 anos; previa também a progressiva extinção do cargo, por vacância, sendo vedada a admissão de novos ADI a partir da vigência da referida Lei. Em 2010, porém, os referidos artigos foram declarados "inconstitucionais" pelo Tribunal de Justiça do Estado de São Paulo, com base em idêntico argumento utilizado pelo CNE, isto é, a exigência de ingresso por concurso público específico para o cargo.

A expectativa de muitos certamente se viu frustrada, o que talvez explique o fato de que $49 \%$ dos ADI entrevistados neste estudo não tenham dado sequência à sua formação em nível superior. Em 2014, a SME de Mauá abriu edital público para provimento de novos cargos de ADI nas creches, diante da crescente demanda por vagas e a consequente superlotação das salas, como pontuado por Poloni (2017). Se, como contatamos em nosso levantamento, $73 \%$ das ADI ingressaram há menos de 2 anos no cargo, e mais de $50 \%$ delas possui diploma em Pedagogia, parece claro que parte considerável dessas profissionais dispunha dos pré-requisitos necessários para o exercício do "magistério", caso o município tivesse feito essa opção para suprir a carência de profissionais em suas creches.

Embora “absolutamente necessárias”, o atual Plano Municipal de Educação (MAUÁ, 2015) não faz nenhuma referência a essas trabalhadoras. Por não se enquadrarem na categoria do "magistério", na carga horária de 40 horas semanais das ADI não é prevista sua participação em atividades de planejamento e outras atividades pedagógicas. Ao serem indagadas, $43 \%$ afirmam participar do planejamento das atividades; $77 \%$ trocam regularmente experiências de trabalho com colegas; e 63\% das ADI confirmam que participam das discussões, com as professoras e equipe gestora, a respeito do desenvolvimento e aprendizagem das crianças. Os depoimentos das ADI das creches de Mauá indicam que, para além das tarefas de cuidar, no dia a dia das escolas se veem envolvidas com atividades que 
competem exclusivamente às professoras, ou seja, à educação. E não poderia ser diferente, pois, como postulam as DCNEI, a criança é mesmo “indivisível”.

Tais contradições e dilemas, vividos em muitos outros municípios, expressam as ambiguidades e imprecisões das políticas de educação infantil ainda não equacionadas pelos poderes públicos. Além disso, refletem a incoerência dos discursos oficiais que, insistentemente, reiteram o compromisso com a qualidade da educação, a valorização de seus profissionais e a democratização das relações na escola. É o que também promete o RCE (Referencial Curricular de Educação) de Mauá, ao proclamar a importância do "trabalho em equipe, construindo relações democráticas e cooperativas, pois, sentindo-se autores, todos se comprometem com o projeto educacional que está sendo implantado na rede escolar" (MAUÁ, 2012, p.6).

\section{Considerações Finais}

Iniciamos este texto com a pergunta: afinal, a quem compete cuidar e educar as crianças pequenas em creches públicas? A questão, assim formulada, teve o propósito de problematizar a persistente divisão do trabalho entre professoras e "suas" auxiliares, pois este é um dos fatores que se interpõem à concretização do princípio da indissociabilidade do binômio cuidar-educar, já transformado em slogan esvaziado de sentido nos discursos sobre educação infantil no Brasil.

Mesmo que essa questão conceitual mereça ainda ser melhor elaborada, o fato é que aqueles que colocam a mão na massa, no dia a dia das instituições infantis, sabem e reconhecem a impossibilidade de separar o ato de cuidar do de educar. Cuidar do outro não é atividade técnica, mas pressupõe acionar, por antecipação, uma série de providências que se relacionam a hábitos, valores e conhecimentos considerados bons, necessários ou úteis com referência a um universo cultural que as orienta. E essa sensibilidade já é suficiente para identificar, no ato de cuidar, a sua dimensão educativa.

Portanto, as cisões e dicotomias possivelmente identificadas nas práticas das instituições de educação infantil não demandam, antes de tudo, "mais formação". Essa tem sido a aposta mais comum, sobretudo dos poderes públicos, para encontrar "soluções" para problemas cuja origem não reside na falta de entendimento das profissionais que têm, cotidianamente, essas tarefas a seu cargo. Subjacente a essa aposta, sustenta-se a tese, formulada ingênua ou propositadamente, de que os responsáveis por tais dicotomias seriam os 
próprios educadores. Ou, ainda, com base nela, constroem-se argumentos convincentes para tirar do foco os reais empecilhos à sua superação.

O problema vem de longe, de nossas tradições históricas e culturais assentadas sobre concepções marcadas por desigualdades de classe e de gênero, e em práticas que reproduzem preconceitos e mantém inalteradas estruturas hierárquicas e de controle social. Nas creches, a cisão do binômio cuidar-educar expressa os valores e a concepção de mundo que divide e hierarquiza o trabalho intelectual e manual. Na esfera das práticas, esse modelo tanto tem o potencial de reproduzir, no imaginário das profissionais de educação, falsas relações de poder calcadas nessa premissa, como o de promover o sentimento de colaboração para "dar conta do recado", o que se traduz em sobrecarga e exploração do trabalho de ambas. Nos dois casos, a questão permanece não resolvida, pois é externa à instituição.

A tradição histórica e cultural a que nos referimos se faz presente nas ambiguidades propositais esquecidas no corpo da Lei, no hibridismo das orientações curriculares resultantes da tentativa de conciliar interesses políticos de grupos em disputa e nos obstáculos e artifícios jurídicos que favorecem e possibilitam a manutenção de estruturas reprodutoras de injustiças e desigualdades sociais. Neste texto, procuramos demonstrar o funcionamento dessa lógica que fomentou, no passado, práticas assumidamente assistencialistas e que, hoje, se travestem de discursos pseudo-progressistas proclamados sobre bases precárias e instáveis.

$\mathrm{Na}$ tentativa de cindir o incindível, a divisão e hierarquização das funções de professores e auxiliares se desdobra em várias outras cisões que ferem os objetivos e princípios enunciados nos documentos oficiais: o princípio da indissociabilidade cuidareducar, o princípio da relação teoria e prática nos processos formativos, o princípio do trabalho coletivo e participativo nas escolas e, em última instância, o da gestão democrática.

O exemplo de Mauá é mais um caso ilustrativo de uma fenda ainda não suturada pelas políticas públicas educacionais brasileiras. Passado e presente se veem frente a frente em meio às ambiguidades jurídicas e políticas que persistem como obstáculos à superação de uma tradição que retorna, sob novos formatos e narrativas, de nosso (in)consciente coletivo.

\section{Referências}

BARRETTO, Elba Siqueira de Sá. Políticas de formação docente para a educação básica no Brasil: embates contemporâneos. Rev. Bras. Educ., Rio de Janeiro, v. 20, n. 62, p. 679701, set. 2015. Disponível em: <http://dx.doi.org/10.1590/S1413-24782015206207> Acesso em: 11 Out. 2017. 
BONETTI, N. Leis de diretrizes e bases e suas implicações na formação de educadores de educação infantil. In: MARTINS FILHO, A. J. (Org.). Criança pede respeito. Porto Alegre: Mediação, 2005, p. 109-160.

BRASIL. Constituição (1988) Emenda Constitucional N. 53, de 19 de dezembro de 2006. Dá nova redação aos arts. $7^{\circ}, 23,30,206,208,211$ e 212 da Constituição Federal e ao art. 60 do Ato das Disposições Constitucionais Transitórias., Brasília, DF, D.O.U. de 20 de dezembro de 2006, p. 5.

BRASIL. [Presidência da República]. Lei N. 8.069, de 13 de julho de 1990. Dispõe sobre o Estatuto da Criança e do Adolescente de dá outras providências. Brasília, DF, D.O.U., de 16 de julho de 1990, Seção 1 [retificado em 27 de setembro de 1990].

Brasil. Ministério da Educação e do Desporto Política de educação infantil. Brasília, MEC/SEF/DPE/COEDI, 1994.

BRASIL. [Presidência da República]. Lei 9.394, de 20 de dezembro de 1996. Estabelece as diretrizes e bases da educação nacional. Brasília, DF, D.O.U. de 23 de dezembro de 1996.

BRASIL. [Ministério da Educação e do Desporto. Secretaria de Educação Fundamental]. Referencial Curricular Nacional para a Educação Infantil / Ministério da Educação e do Desporto, Secretaria de Educação Fundamental. — Brasília: MEC/SEF, 1998.

BRASIL. [Ministério da Educação. Conselho Nacional de Educação]. CNE. Resolução CEB 1/99. Institui as Diretrizes Curriculares Nacionais para a Educação Infantil. Brasília, DF, D. O.U. de 13 de abril de 1999. Seção 1, p. 18.

BRASIL. [Ministério da Educação. Secretaria de Educação Básica]. Parâmetros Nacionais de Qualidade para a educação infantil. V. 2. Ministério da Educação. Secretaria de Educação Básica, Brasília, DF, 2006. 44p.

BRASIL. [Ministério da Educação. Conselho Nacional de Educação]. Parecer CNE/CEB No CNE/CEB n. 24/2007. Consulta sobre como deve ser entendida a designação "magistério da Educação Básica", para fins de destinação de, pelo menos, 60\% dos recursos do FUNDEB. Brasília, DF, D.O.U. de 24 de março de 2008.

BRASIL. [Ministério da Educação. Conselho Nacional de Educação]. Parecer CNE/CEB No. 21/2008, de 8 de outubro de 2008. Consulta sobre profissionais de Educação Infantil que atuam em redes municipais de ensino. Brasília, DF, 2008.

BRASIL. [Ministério da Educação. Secretaria de Educação Básica]. Indicadores da Qualidade na Educação Infantil. Ministério da Educação. Secretaria de Educação Básica, Brasília, DF, 2009. 64p., set. 2017.

BRASIL. [Ministério da Educação. Conselho Nacional de Educação]. Parecer CNE/CEB No. 7/2011, de 2 de junho de 2011. Profissionais da Educação Infantil: possibilidades de sua inclusão na carreira do magistério da Educação Básica e consequente remuneração com recursos do FUNDEB. Brasília, DF, 2011. 
BRASIL. [Presidência da República]. Lei. No. 13.415, de 16 de fevereiro de 2017, Brasília, DF: D.O.U. de 17 de fevereiro de 2017(a), Seção 1, p. 1 .

BRASIL. [Ministério da Educação]. Portaria No 826, de 7 de julho de 2017, Brasília, DF: D.O.U., 10 jul.2017(b), nº 130, Seção 1, p. 20.

CAMPOS, Maria Malta. Educar e cuidar: questões sobre o perfil do profissional de educação infantil. In: BRASIL [Ministério da Educação]. Por uma política de formação do profissional de Educação Infantil. Brasília: MEC/SEF/DPE/COEDI, 1994.

CAMPOS, Maria Malta et al. A qualidade da educação infantil: um estudo em seis capitais Brasileiras. Cad. Pesqui., São Paulo, v. 41, n. 142, p. 20-54, abr. 2011. Disponível em:< http://dx.doi.org/10.1590/S0100-15742011000100003 > . Acesso em: 11 Out. 2017.

CAMPOS, Maria Malta; ROSEMBERG, Fúlvia. Critérios para um atendimento em creches que respeite os direitos fundamentais das crianças. 6a. ed. Brasília: MEC, SEB, 2009, 44p. (1a. ed. 1995). Disponível em: <http://portal.mec.gov.br/dmdocuments/direitosfundamentais.pdf> Acesso em: 27 set.2017.

CAMPOS, Maria Malta; ROSEMBERG, Fúlvia; FERREIRA, Isabel Morsoletto. Creches e pré-escolas no Brasil. São Paulo: Cortez, 1995.

CAMPOS, Maria Malta et al. A qualidade da educação infantil: um estudo em seis capitais Brasileiras. Cad. Pesqui., São Paulo, v. 41, n. 142, p. 20-54, abr. 2011. Disponível em:< http://dx.doi.org/10.1590/S0100-15742011000100003.> Acesso em: 04 out.2017.

CERISARA, Ana Beatriz. O Referencial Curricular Nacional para a Educação Infantil no contexto das reformas. Educ. Soc., Campinas, vol. 23, n. 80, p. 326-345, set., 2002. Disponível em: <http://www.scielo.br/pdf/es/v23n80/12935.pdf> Acesso em: 25 set. 2017.

CERISARA, Ana Beatriz. Educar e cuidar: por onde anda a educação infantil? Perspectiva, Florianópolis, v. 17, n. especial, p. 11-24, jul./dez. 1999a. Disponível em:

<http://dx.doi.org/10.5007/\%25x > Acesso em: 30 set. 2017.

CERISARA, Ana Beatriz. Dinâmica das relações entre profissionais de educação infantil. Perspectiva. Florianópolis, v. 17. n. Especial, p. 109-138, jul./dez 1999b. Disponível em: <http://dx.doi.org/10.5007/\%25x > Acesso em: 30 set. 2017.

GATTI, Bernadete A.; NUNES, Marina Muniz R. (Org.). Formação de professores para o ensino fundamental: estudos de currículos das licenciaturas em pedagogia, língua portuguesa, matemática e ciências biológicas. São Paulo: FCC/DPE, 2009.

GATTI, Bernadete Angelina; BARRETO, Elza Siqueira de Sá; ANDRÉ, Marli E. D. Afonso. Políticas docentes no Brasil: um estado da arte. Brasília: Unesco, 2011, p. 31-48.

GOMES, M. de O. Formação de professores na educação infantil. São Paulo: Cortez, 2009. 
KISHIMOTO, T. M. O sentido profissionalizante para o educador na infância. In:

BARBOSA, R. L. L. Trajetórias e perspectivas da formação de educadores. São Paulo:

UNESP, 2004, p. 329-346.

KRAMER, Sonia (Org.). Profissionais de educação infantil: gestão e formação. São Paulo: Ática, 2005.

KUHLMANN Jr., Moysés. Infância e educação infantil: uma abordagem histórica. Porto Alegre: Mediação, 1998. 209p.

KUHLMANN Jr., Moysés. Educação infantil e Currículo. In: FARIA, Ana Lucia Goulart de; PALHARES, Marina Silveira (Org.). Educação infantil pós-LDB: rumos e desafios. Campinas/São Carlos/Florianópolis: 4a. ed. Autores Associados - FE/Unicamp/Editora da UFSCar/Editora UFSC, 2003, p. 51-65. (Coleção Polêmicas do Nosso Tempo, 62).

KUHLMANN Jr., Moysés. Histórias da educação infantil brasileira. Revista Brasileira de Educação, Rio de Janeiro, n.14, p. 5-18, mai./ago. 2000. Disponível em: <http://www.scielo.br/pdf/rbedu/n14/n14a02> Acesso em: 12 out. 2017.

LORDELO, Eulina da Rocha; CARVALHO, Ana Maria A.; KOLLER, Helena. (Org.). Infância brasileira e contextos de desenvolvimento. São Paulo: Casa do Psicólogo; Salvador, BA: Editora da Universidade Federal da Bahia, 2002.

MACHADO. Maria Lucia de A. Criança pequena, educação infantil e formação dos profissionais. Perspectiva. Florianópolis, v.17, n. Especial, p. 85-98, jul./dez. 1999.

MACHADO. Maria Lucia de A. Educar crianças pequenas. Em busca de um novo perfil de professor. Retratos da Escola, Brasília, v. 2, n. 2-3, p. 121-131, jan./dez. 2008.

MARIN, Alda Junqueira; GIOVANNI, Luciana. M. Expressão escrita de concluintes de curso universitário para formar professores. Cadernos de Pesquisa, v. 37, n. 130, p. 15-41, jan./abr. 2007. Disponível em: <http://dx.doi.org/10.1590/S0100-15742007000100003.> Acesso em: 30 set. 2017.

MARIN, Alda Junqueira; GIOVANNI, Luciana M. Formação de professores para o início da escolarização: fragilidades. InterMeio, Campo Grande, v. 19, n. 38, p. 52-68, jul./dez 2013. Disponível em:

<http://www.intermeio.ufms.br/ojs/index.php/intermeio/article/view/348/295 > Acesso em: 27 set. 2071.

MAUÁ. [Prefeitura do Município de Mauá]. Decreto n. 6.433 de 28 de maio de 2003, Regulamenta Sistema de Gerenciamento de Desempenho dos Servidores Públicos do Município de Mauá e dispõe sobre a descrição detalhada das atribuições dos cargos. Mauá, SP, 2003.

MAUÁ. [Prefeitura do Município de Mauá]. Lei. No. 4.135, de 2 de fevereiro de 2007. Estabelece o Estatuto do Magistério Público do Município de Mauá e dá outras providências. Mauá, SP, 2007. 
MAUÁ. [Prefeitura do Município de Mauá]. Referencial Curricular da Educação de

Mauá. Secretaria Municipal de Educação, Mauá, SP, 2012.

MAUÁ. Secretaria Municipal de Mauá. Projeto político-pedagógico. Escola Municipal Doutora Darci Aparecida Fincatti Fornari, Mauá, 2015 (mimeo).

MAUÁ. [Prefeitura do Município de Mauá]. Lei. No. 5097 de 16 de outubro de 2015. Plano Municipal de Educação do Município de Mauá, Mauá, SP, 2015.

MAUÁ. [Secretaria de Educação de Mauá]. Documento Orientador: Planejamento 2016 (mimeo).

MONTENEGRO, Thereza. Educação Infantil: a dimensão moral da função de cuidar. Psic. da Ed., São Paulo, 20, $1^{\circ}$ sem. de 2005, p. 77-101. Disponível em: <http://pepsic.bvsalud.org/scielo.php?script=sci_arttext\&pid=S1414-69752005000100005> Acesso em: 01 out. 2017.

NUNES, Maria Fernanda Rezende; CORSINO, Patrícia; KRAMER, Sonia. Educação infantil e políticas municipais: um estudo longitudinal. Cad. Pesqui., São Paulo, v. 43, n. 148, p. 152175, abr. 2013. Disponível em: 〈http://dx.doi.org/10.1590/S0100-15742013000100008.> Acesso em: 01. Out. 2017.

POLONI, Maria José. Creche: do direito à educação à judicialização da vaga. Tese (Doutorado em Educação). 2017, 277f. Universidade Nove de Julho - UNINOVE, São Paulo, 2017.

ROCHA, Eloisa Acires Candal. A pedagogia e a educação infantil. Revista Brasileira de Educação, Rio de Janeiro, n. 16, p. 27-34, jan./abr., 2001. Disponível em: <http://www.scielo.br/pdf/rbedu/n16/n16a03> Acesso em: 25 set. 2017.

ROSEMBERG, Fúlvia. Movimento de mulheres e a abertura política no Brasil. Cad.Pesq., São Paulo, n. 51, p. 73-79, nov. 1984.

SCHIFINO, Reny Scifoni. A luta das mulheres operárias por creche: do "Balde" ao Direito à Educação. Olh@ares, Guarulhos, v. 4., n.2, p. 94-111, nov. 2016. Disponível em: <http://www.olhares.unifesp.br/index.php/olhares/article/view/620/205> Acesso em: 25 set. 2017.

SAVIANI, Dermeval. O vigésimo ano da LDB. As 39 leis que a modificaram. Revista Retratos da Escola, Brasília, v. 10, n. 19, p. 379-392, jul./dez. 2016. Disponível em: <http://dx.doi.org/10.22420/rde.v10i19.717> Acesso em: 20 set. 2017.

TIRIBA, Lea. Educar e cuidar ou, simplesmente, educar: buscando a teoria para compreender discursos e práticas. In: REUNIÃO ANUAL DA ANPED, 28., 2005, Caxambu. Anais... Rio de Janeiro: Anped, 2005. Disponível em:

<http://www.anped.org.br/sites/default/files/gt07939int.pdf> Acesso em: 27 Set.2017.

VYGOTSKY, Lev Semionovich. A formação social da mente: o desenvolvimento dos processos superiores. São Paulo: Martins Fontes, 1988. 


\section{$\underline{\text { SOBRE AS AUTORAS }}$}

\section{Sanny Silva da Rosa}

Doutora em Educação pela Pontifícia Universidade Católica de São Paulo (PUC-SP). PósDoutora em Educação pelo Instituto de Educação da Universidade de Londres (UK), na Inglaterra. Professora e pesquisadora do Programa de Pós-Graduação em Educação da Universidade Municipal de São Caetano do Sul (USCS). Líder do grupo de pesquisa Gestão Democrática e Qualidade Social da Educação Básica, da USCS. orcid.org/0000-0001-50446156. E-mail: professorasanny@gmail.com

\section{Fernanda Feliciano de Andrade}

Mestre em Educação pela Universidade Municipal de São Caetano do Sul (USCS). Membro do Grupo de Pesquisa Gestão Democrática e Qualidade Social da Educação Básica da USCS. Professora de educação infantil da rede municipal de São Bernardo do Campo e do município de Mauá, SP. E-mail: anfere@bol.com.br 